\title{
Financing the Sustainable Energy Transition
}

\author{
Alexander Van de Putte, Akshu Campbell-Holt, and George Littlejohn
}

\section{Indroduction}

In The Perfect Storm: Navigating the Sustainable Energy Transition, the authors argue that for the energy transition to be sustainable, the five capital stocks-natural, manufactured, human, social and financial—need to be grown (or maintained) and balanced simultaneously (Van de Putte et al. 2017).

What is considered sustainable energy though is not necessarily well understood. For the purpose of this chapter, we will argue that the end-game for the sustainable energy future is a global renewable energy internet comprised of five integrated layers: (1) largely distributed renewable energy generation technologies, such as wind, solar and hydro, (2) electricity transmission and distribution network infrastructure, (3) energy storage solutions and smart energy routers, (4) active network management software to manage and balance loads and (5) mobile and stationary sensors and smart terminals (Van de Putte and Nematova 2017).

To make the transition to a global renewable energy internet a reality, it is also necessary to make the current energy system more sustainable by employing Circular Economy (CE) ideas. According to the Ellen MacArthur Foundation (2013), a circular economy 'seeks to rebuild capital, whether this financial, manufactured, human, social or natural'. 'The rebuilding of capital is achieved by reusing, reducing and recycling waste and the shift from a 'cradle-to-grave' to a 'cradle-to-cradle'

${ }^{1}$ https://www.ellenmacarthurfoundation.org/circular-economy (accessed 4 July 2016).

A. Van de Putte $(\varangle) \cdot$ A. Campbell-Holt
Astana International Financial Centre, Nur-Sultan, Kazakhstan
e-mail: alexander.van.de.putte@ sustainable-foresight.com
G. Littlejohn
Chartered Institute for Securities and Investments, London, UK

A. Van de Putte

IE Business School, Madrid, Spain 
philosophy. The benefits of the circular economy cannot be ignored in the transition towards a sustainable global energy environment. McKinsey estimates that between 2016 and 2030, apart from the environmental, social and human capital benefits, the net economic benefits are estimated at $€ 1.8$ trillion, ${ }^{2}$ or in excess of $€ 120$ billion per year or $0.8 \%$ of global GDP. For developing countries, especially natural resource-rich economies, this could be twice as much.

Most of the energy demand growth will come from developing countries. Developing countries are home to more than 6 billion people, ${ }^{3}$ and especially natural resource-rich countries hold the key to sustainable development. This is because these countries tend to be at the early stages of climbing the 'energy ladder'. The energy ladder, first described by Shell in the early 1980s, shows the relationship between primary energy consumption per capita and Gross Domestic Product (GDP) per capita and follows an S-curve (Van de Putte 2010).

As capital markets and venture capital financing is well developed in OECD markets, and given that energy demand growth will primarily come from developing countries, this chapter largely focuses on financing the sustainable energy transition in the developing world. If financial resources would be properly channelled, developing countries could leapfrog the sustainable energy transition.

\section{The Tables Are Turning}

The ratification of the Paris Agreement by nearly 94\% of the world demonstrates a strong global commitment from most countries to achieve the United Nation's Sustainable Development Goals (UNFCCC 2019). The challenge, however, is the enormous investment requirement which is estimated between $\$ 5$ trillion and \$7 trillion per year (UNCTAD 2014) and channelling investments were required.

Additionally, a growing body of studies demonstrates that the new generation of investors with changing mindsets provides increasing optimism for the inclusion of sustainability in investment decisions. This, together with the superior returns potential from sustainable investments compared to traditional investments, emphasises a strong match between requirements and investors-is it possible to leverage this match and what challenges lie ahead?

\subsection{Countries Have Made Global Commitments}

United Nations-led initiatives including the Paris Agreement, the Kyoto Protocol and the Sustainable Development Goals have seen widespread global commitment

\footnotetext{
${ }^{2}$ https://www.mckinsey.com/business-functions/sustainability/our-insights/europes-circulareconomy- opportunity (accessed 4 July 2016).

${ }^{3}$ https://population.un.org/wpp (United Nations 2019a).
} 
in recent years. While both the Paris Agreement and the Kyoto Protocol are targeted towards addressing climate change, the Kyoto Protocol established emissions reduction commitments for developed nations while the Paris Agreement applied to all countries-developing and developed. Out of 197 Parties to the United Nations Framework Convention on Climate Change (UNFCCC), 185 have signed up to the Paris Agreement and undertaken commitments and identified their Nationally Determined Contributions (NDCs) (UNFCCC n.d.).

There are several bodies that have recommended solutions to tackle the $\mathrm{CO}_{2}$ emissions and climate change but now is the time to take collective action. One such solution is identified in the World Energy Outlook 2018 as the Sustainable Development Scenario ${ }^{4}$ that presents an integrated approach to maintain $\mathrm{CO}_{2}$ levels at the same level as in 2017 and achieve internationally agreed objectives on climate change, air quality and universal access to modern energy. The WEO 2018 highlights that a sustainable development scenario which is aligned with the Paris Agreement can be made possible but will be heavily determined by the actions undertaken by governments. The prerequisites for this will not only include the joint political will globally but also the mammoth funding required for the implementation of NDCs. Some of the key considerations in this scenario include (International Energy Agency 2018):

- renewable energy technologies to lead the way in providing universal access to energy and thereby increasing the share of renewables in the power mix from one-quarter in 2017 to two-thirds in 2040;

- implementation of economically viable options to improve efficiency in the energy sector thereby maintaining overall demand in 2040 at the same level as at 2017 and

- for the first time in the WEO, clean water is examined as a dimension including the energy required to provide universal access to clean water and sanitation.

\subsection{Investors Are Changing, Mindsets Are Changing}

A world that is faced with growing challenges is also in the midst of an intergenerational wealth transfer estimated at $\$ 30$ trillion from baby boomers to their children, a majority being millennials, and is expected to take place over the next two or three decades (MSCI 2017). The millennial generation is seeking far more than mere financial factors-responsible investments and positive environmental, social and governance impacts alongside financial returns as evidenced by some of the recent revolutionary findings.

\footnotetext{
${ }^{4}$ According to the World Energy Outlook (WEO), the scenarios (Current Policies Scenario, New Policies Scenario and Sustainable Development Scenario) do not aim to forecast the future but provide a way of exploring different possible futures, the levers that could bring them about, and the interactions that arise across a complex energy system. The base year for projections in all scenarios is 2016 .
} 
According to a Morgan Stanley study (MSCI 2017), the three common objectives among sustainably-minded investors are

1. integration of environmental, social and governance (ESG) factors because they believe that companies with strong ESG factors are better managed and that this may improve their investment results;

2. reflection of personal values in relation to ethical, social, religious or political beliefs and

3. selection of investments with a positive impact on environmental, social and political challenges and thereafter the ability to monitor those investments based on norms set through frameworks (e.g. Paris Agreement, UN Sustainable Development Goals).

The Global Sustainable Investment Review 2018(GSIR 2018) (Global Sustainable Investment Alliance 2017) highlights the widespread global interest and engagement in sustainable investing which is an investment approach that considers environmental, social and governance (ESG) factors in making investment decisions. GSIR 2018 covers information for five markets (Europe, USA, Canada, Japan, and Australia and New Zealand) collectively managing sustainable investing assets worth \$30.7 trillion as of early 2018. This is a 34\% increase since 2016 with Japan and USA leading the way. In Japan, sustainable assets grew at a staggering 308\% since 2016 and the corresponding growth rate in the USA was $38 \%$, with other regions continuing to rise but experiencing growth at a slower pace. On the other hand, at the start of 2018, the proportion of sustainable assets in relation to total assets grew in almost every region with Canada and Australia and New Zealand consisting of sustainable assets as the majority of their overall assets. The only region that had a slight decline in this proportion was Europe, however, with nearly half of the global sustainable and responsible investing assets domiciled in Europe, it continues to manage the highest proportion of sustainable assets (GSIA 2017).

GSIR 2018 also indicated that the top sustainable investment strategy globally continues to be 'negative or exclusionary screening' ${ }^{5}$ with $\$ 19.8$ trillion assets under management, followed by 'ESG integration' 6 and 'corporate engagement and shareholder action, ${ }^{7}$ with $\$ 17.5$ trillion and \$9.8 trillion assets under management, respectively. Impressive growth rates in assets across almost all other strategies were reported with the exception of "norms-based screening' ${ }^{8}$ which declined by $24 \%$

\footnotetext{
${ }^{5}$ GSIA defines the 'negative or exclusionary screening' strategy as the 'exclusion from a fund or portfolio of certain sectors, companies or practices based on specific ESG criteria'.

${ }^{6}$ GSIA defines the 'ESG integration' strategy as 'the systematic and explicit inclusion by investment managers of environmental, social and governance factors into financial analysis'.

${ }^{7}$ GSIA defines the 'corporate engagement and shareholder action' strategy as 'the use of shareholder power to influence to influence corporate behaviour, including through direct corporate engagement (i.e. communicating with senior management and/or boards of companies), filing or co-filing shareholder proposals, and proxy voting that is guided by comprehensive ESG guidelines'. ${ }^{8}$ GSIA defines the 'norms-based screening' as the 'screening of investments against minimum standards of business practice based on international norms, such as those issued by the OECD, ILO, UN and UNICEF'.
} 
from $\$ 6.2$ trillion to $\$ 4.7$ trillion in assets. These trends support a growing change in mindsets among investors globally.

Despite the USA's intent to withdraw from the Paris Agreement, there are strong signs of increasing interest and awareness in sustainable investing among individual investors in the USA. A survey conducted with 1,000 US individual investors by Morgan Stanley's Institute for Sustainable Investing (2017) provides for a positive and pro-sustainable future as the results showed that

- awareness and interest in sustainable investing has grown steadily since 2015;

- among individual investors, 75\% are interested in sustainable investing and the level of interest among millennials is even higher at $86 \%$;

- almost three-quarters $(71 \%)$ of individual investors believe companies with robust sustainability practices are better long-term investments and

- the USA saw a spike in sustainable, responsible and impact investing between 2014 and 2016 growing at a rate more than 33\% amounting to $\$ 8.72$ trillion.

These trends are on a rise and if applied across the world and across all stakeholders far beyond the investor community, it might rest with the voters' ability to choose an administration which is pro-sustainable_-an interesting area to look out for especially in the 2020 elections in the USA.

ESG investments, Socially Responsible Investing (SRI) and impact investing, albeit differing from one another in their definitions and used interchangeably, are all components of sustainable investing and are strong contenders to become the new norm in making investment decisions. This also makes a strong argument for the likelihood of a future by 2030, if not earlier, where companies that deviate from ESG, SRI and impact investing principles would become the outliers and therefore not favoured by stakeholders - not only by the investor community but across the entire ecosystem including customers, suppliers, shareholders, consumers and the wider community. Studies and surveys demonstrate that the interest in ESG, SRI and impact investing is more pronounced among millennials and as they increasingly take up decision-making roles, positions of influence and control assets, they are bound to become a strong driving force for sustainability. Do these trends bring about a perfect match between investors and investment requirements for the sustainable development of economies? This is a question to be addressed later in this chapter.

\subsection{ESG, SRI and Impact Investments Outperform Traditional Investments}

As described above, the recent trends and developments in ESG, SRI and impact investing demonstrate that sustainability is increasingly becoming mainstream. While investors are being virtuous by increasingly seeking ESG, SRI and impact investments, they are also making money by doing what they believe to be the right thing. According to a growing number of studies, ESG, SRI and impact investing 
are providing better returns compared to traditional investments. 'Traditional investments' in this chapter indicate investments that do not consider pro-sustainable factors including, but not limited to, environmental, social, governance, ethical and norms, alongside financial factors.

Europe's largest asset manager by assets under management, Amundi, that has yet again received the top rating $(\mathrm{A}+)^{3}$ in 2018 for its responsible investment approach, ${ }^{9}$ has championed responsible investing by including it at the core of its identity. Between 2010 and 2017, Amundi conducted a study (Amundi 2018) which considered investment universes covered by MSCI indices (MSCI North America, MSCI EMU, MSCI Europe ex EMU, MSCI Japan and MSCI World) and applied three different strategies - active management, passive management and factor investingand based its analysis on ESG criteria. The analysis found that while ESG investments produced negative excess return compared to non-ESG investments during the period from 2010 to 2013, 2014 was a turning point where ESG investments outperformed non-ESG investments. The results of the analysis showed that, between 2014 and 2017, being a 'responsible investor' and managing portfolios based on the ESG criteria would have resulted in annualised excess return of 3.3\% in North America and a remarkable $6.6 \%$ in Europe. While Amundi promotes ESG-induced portfolios, it cautions while applying these factors to avoid reducing the investment universe beyond the point that could negatively impact diversification and performance.

In another study (Giese et al. 2019), a research team at MSCI looked at the attributes of ESG investments that led to positive financial effects and found that companies with robust ESG practices demonstrated the following characteristics:

- Higher profitability: When compared with low ESG-rated companies, higher ESG-rated companies had a competitive edge and generated better returns that usually resulted in higher profitability and dividend payments.

- Lower risk: An observation of companies within the MSCI World Index over a 10year period demonstrated that high ESG-rated companies had a lower frequency of severe incidents such as drawdowns more than $95 \%$ or bankruptcy.

- Lower volatility: Because of better risk controls associated with high ESG-rated companies, they have fewer severe incidents of fraud, corruption, embezzlement and litigation cases.

In addition to Amundi, other global asset managers including Blackrock, BNP Paribas, Vanguard and Fidelity Investments have launched ESG funds. According to data provided by Morningstar, mutual funds based on ESG criteria surpassed the $\$ 1$ trillion mark in 2018 with assets under management rising by $60 \%$ since 2012 from $\$ 655$ billion to $\$ 1.05$ trillion.

January 2019 witnessed another milestone for sustainable investment when S\&P Dow Jones Indices launched the S\&P 500 ESG Index. In the first half of 2019 alone, S\&P Dow Jones Indices has launched six ESG indices (S\&P 2019) with global

\footnotetext{
${ }^{9}$ https://www.amundi.com/int/ESG.
} 
coverage. ${ }^{10}$ Similar to the S\&P 500 Index, in the S\&P 500 ESG Index companies are ranked by their ESG scores and excluded if they do not meet the criteria as defined in the Index. Companies can be excluded from the S\&P 500 ESG index for reasons including:

- failure to meet the required ESG scores;

- disqualifying United Nations Global Compact (UNGC) scores or

- business activities listed in the exclusion list such as tobacco production/sales or controversial weapons (e.g. cluster weapons, landmines and nuclear weapons), or an ownership stake of $25 \%$ or more in another company involved in these activities.

In April 2019, several notable companies were removed from the S\&P 500 ESG Index, including Facebook, Wells Fargo, Oracle and IBM-Facebook being the largest with a weight of $2.5 \%$ in the index a day before it was excluded (Steadman 2019). As a result of the recent privacy protection concerns, such as a lack of transparency on collecting and sharing private user information, Facebook did not meet the requirement to remain in the S\&P 500 ESG Index. Despite Facebook scoring high on the environment score, its aggregate was brought down by the social and governance factors which are weighted higher for tech companies.

In summary, a growing number of studies demonstrate that high ESG-rated companies are associated with positive characteristics that all stakeholders look for in any company or while making investment decisions. Together with the pronounced interest from investors who are seeking to make a positive impact through their investments, ESG, SRI and impact investing all have the likelihood of being the new norm in making investment decisions and in voting practices. Additionally, with an increasing adoption rate of ESG, SRI and impact investing among investors and leading global asset managers, sustainability will soon become the central topic among institutional investors, policymakers, regulators, government agencies and corporations alike. Importantly, investors can now do the right thing-socially responsible and sustainable investing - without settling for sub-optimal returns.

\section{Channelling Investments to Meet Global Energy Demand Sustainably Remains a Challenge}

With the world population projected to reach 9.2 billion by 2040 (UN 2019a) - a nearly $20 \%$ increase from the 2019 levels_-an upsurge in the demand for energy consumption is inevitable and the demand is estimated to increase by more than a quarter by 2040 predominantly in developing countries led by India. Despite efforts towards combating climate change, 2017 recorded a rise in carbon emissions from

\footnotetext{
${ }^{10}$ The six indices are S\&P 500 ESG Index, S\&P Global 1200 ESG Index, S\&P Europe 350 ESG Index, S\&P Japan 500 ESG Index, S\&P/ASX 200 ESG Index and S\&P Developed Ex-North America \& Korea LargeMidCap ESG Index.
} 
the global energy industry at the fastest rate since 2011 and the upward trajectory is continuing. Global $\mathrm{CO}_{2}$ emissions are forecast to rise by a near-record amount in 2019 (The Guardian 2019). These trends pose alarming global threats and they attest that efforts thus far are inadequate to achieve global commitments and are a reminder that it has never been more critical to transition to a cleaner and more efficient energy industry in the context of meeting global sustainability targets.

\subsection{Current Overreliance on Fossil Fuels}

The global energy demand is still being served mostly by fossil fuels, such as oil $(30 \%)$, coal $(27 \%)$ and gas $(20 \%)$ (ENI 2018), which poses a growing concern in relation to carbon emissions and, consequently, climate change.

The Paris Agreement becomes binding only through ratification. Despite being signatories to the Paris Agreement, as of June 2019, 11 countries $^{11}$ were yet to formally ratify the Paris Agreement and these countries are collectively responsible for more than a tenth of global emissions which presents added concern and raises questions regarding their commitment to achieve global sustainable goals. Of the 11 countries, Russia, Turkey and Iran are notably some of the largest Global Greenhouse Gas (GHG) emitters (Apparicio and Sauer 2018). Although the USA has notified its intention to withdraw from the Paris Agreement, it can only officially withdraw after 3 years from the date of the Agreement which means that the USA must stay in the deal until at least 2019. Nonetheless, this demonstrates a lack of commitment from one of the world's biggest offenders in terms of GHG emissions and, according to the Climate Action Tracker, it is almost certain that the USA will miss its NDC target for 2025 due to the lack of implementation of new policies planned by the Obama administration. However, there are studies and surveys that display positive signs among individual investors with their keen interest in sustainable investments.

The Climate Action Tracker, which has been monitoring 32 countries that account for $80 \%$ of the world's greenhouse gas emissions, has reported (Erickson 2018) some alarming findings which establish that actions, thus far, are far from adequate in meeting the climate change goals. In fact, the world's major polluters have made minimal efforts, if any, to meet their commitments and that only seven countries (Morocco, The Gambia, Bhutan, Costa Rica, Ethiopia, India and the Philippines) have made efforts and commitments to class them under either of the two acceptable categories,

\footnotetext{
${ }^{11}$ As of 1 June 2019, the countries yet to formally ratify the agreement were Angola, Eritrea, Iran, Iraq, Kyrgyzstan, Lebanon, Libya, Russia, South Sudan, Turkey and Yemen.
} 
'1.5 ${ }^{\circ} \mathrm{C}$ Paris Agreement Compatible' and ' $2{ }^{\circ} \mathrm{C}$ Compatible', with the other categories on the scale being 'Insufficient', ${ }^{2}$ 'Highly Insufficient' ${ }^{13}$ and 'Critically Insufficient'. ${ }^{14}$

In its latest working paper on global fossil fuel subsidies, the International Monetary Fund (Coady et al. 2019) estimates that the direct ${ }^{15}$ and indirect ${ }^{16}$ fossil fuel $^{1}$ subsidies in 2017 amounted to $\$ 5.2$ trillion, or $6.5 \%$ of global GDP, and that especially the indirect subsidies are likely to increase unless drastic measures are taken to move the world away from fossil fuels. But weaning economies from fossil fuels also requires huge financial investments.

\subsection{Capital Markets in Developing Countries Are Underdeveloped}

It is estimated (UNCTAD 2014, p ix) that the investment requirement to implement the Sustainable Development Goals (SDGs) ${ }^{17}$ in developing countries alone is between $\$ 3.3$ trillion and $\$ 4.5$ trillion per year and faces an annual funding gap of $\$ 2.5$ trillion. In addition to climate change mitigation and adaptation, these costs also account towards basic infrastructure, health, food security and education-elements of sustainable economic development.

Governments and public funds simply cannot meet these astronomical investment requirements making the role of the capital markets and private sector instrumental in bridging the gap. UNCTAD's Investment Policy Framework for Sustainable Development recognises stock exchanges and market infrastructure to be instrumental in meeting these investment needs. However, capital markets in most developing countries still remain underdeveloped. For instance, more than half of the Asian countries are not recognised in the MSCI indices (MSCI 2019a). The development of stock markets will be crucial in mobilising investments since stock exchanges

\footnotetext{
${ }^{12}$ Countries classified under 'Insufficient' are Australia, Brazil, EU, Kazakhstan, Mexico, New Zealand, Norway, Peru, Switzerland and UAE.

${ }^{13}$ Countries classified under 'Highly Insufficient' are Argentina, Canada, Chile, China, Indonesia, Japan, Singapore, South Africa and South Korea.

${ }^{14}$ Countries classified under 'Critically Insufficient' are Russia, Saudi Arabia, Turkey, USA and Ukraine.

${ }^{15}$ Direct subsidies are defined as the cash transfer from governments to industry and amounted to \$296 billion in 2017 (IMF 2019). Direct subsidies are often referred to as pre-tax subsidies, because they reflect the difference between what consumers pay for fuel and the cost to produce the fuel.

${ }^{16}$ Indirect subsidies or post-tax subsidies reflect the difference between what consumers pay for fuel and the full environmental and societal costs of fossil fuels. Indirect subsidies may be perceived as less tangible, but they are both real and increasing.

${ }^{17}$ The United Nations' Sustainable Development Goals (SDGs) are a call for action by all countries to promote prosperity while protecting the planet. 'SDGs are the blueprint to achieve a better and more sustainable future for all. They address the global challenges we face, including those related to poverty, inequality, climate, environmental degradation, prosperity and peace and justice' (United Nations 2019b).
} 
are positioned in the intersection of key stakeholders including the government, policymakers, investors and corporations.

\subsection{Matching Financing with Projects Remains Problematic}

In a recent working paper (Tyson 2018), the Overseas Development Institute (ODI) finds that the lack of bankable projects that meet investment criteria is a key barrier, not the lack of financing. This is found even in countries where international financial institutions play a significant role in providing infrastructural support including technical assistance in developing innovative and new policy approaches, providing new project-preparation facilities, and financing and co-financing of funds and derisking for private investors. This is largely due to (1) the early stages of development of projects, (2) lengthy planning and construction phases, (2) requirements of nonstandard financing and (3) the bespoke and complex nature of the projects making it excessively difficult for investors to understand. These challenges are further compounded especially in developing countries due to the lack of an adequate ecosystem to foster the growth of micro, small and medium-sized businesses, in particular, owing to limited early stage investors, such as venture capitalists, private equity and angel investors, who not only provide financing but also the strategic direction and platforms to grow.

\section{Could There Be a Perfect Match?}

The investment needed to finance a Global Renewable Energy Internet is estimated to be in the range of $\$ 100$ trillion globally until 2050 or close to $\$ 3$ trillion per year (Van de Putte and Nematova 2017; Liu 2015). This seems to be a very significant amount but is relatively small compared to the annual direct ${ }^{18}$ and indirect ${ }^{19}$ subsidies that are channelled into the fossil fuel industry globally.

There is also no shortage of capital or sources of capital to finance the sustainable energy transition. According to the Boston Consulting Group (BCG 2019), global wealth now exceeds $\$ 200$ trillion and since the 2008 global financial and economic crisis, this global wealth has struggled to find bankable projects anywhere in the world. The Global Renewable Energy Internet could provide this opportunity for global investors to make a game-changing contribution to sustainability, while at the

\footnotetext{
${ }^{18}$ Direct subsidies are defined as the cash transfer from governments to industry and amounted to \$296 billion in 2017 (IMF 2019). Direct subsidies are often referred to as pre-tax subsidies, because they reflect the difference between what consumers pay for fuel and the cost to produce the fuel.

${ }^{19}$ Indirect subsidies or post-tax subsidies reflect the difference between what consumers pay for fuel and the full environmental and societal costs of fossil fuels. Indirect subsidies may be perceived as less tangible, but they are both real and increasing.
} 
Table 1 Financing landscape for sustainable projects

\begin{tabular}{|c|c|c|}
\hline Commercial & Development institutions & Government \\
\hline \multirow{3}{*}{$\begin{array}{l}\text { Banks } \\
\text { - Debt/equity, Guarantee on leans, } \\
\text { Funds, } \\
\text { Asset Managers } \\
\text { - Debt/equity, Funds, SPVs, Leases, } \\
\text { Private placements, } \\
\text { Private Equity, Venture Capital } \\
\text { - Equity, Funds, SPVs, Private } \\
\text { placements, } \\
\text { Institutional Investors } \\
\text { - Syndicated loans, private placements, } \\
\text { debt }\end{array}$} & $\begin{array}{l}\text { Multinational } \\
\text { Bilateral } \\
\text { National }\end{array}$ & $\begin{array}{l}\text { - Grants } \\
\text { - PPPs } \\
\text { - Guarantees on loans } \\
\text { - Sovereign debt }\end{array}$ \\
\hline & \multicolumn{2}{|l|}{ Private } \\
\hline & \multicolumn{2}{|l|}{$\begin{array}{l}\text { Project developers } \\
\text { - Equity/leases }\end{array}$} \\
\hline
\end{tabular}

same time providing superior returns in line with the findings of the 2019 Amundi study.

Sources of capital are diverse and growing and include banks, asset managers, private equity, institutional investors, development institutions and government financing (Table 1).

We argue that a perfect match exists between global capital and sustainable projects to rapidly scale the sustainable energy transition if at least three things come together: (1) capital market development in developing countries, (2) government regulation to create a level playing field and (3) a venture capital approach to stimulate sustainable investments and entrepreneurship (Fig. 1).

\subsection{Developing Countries Need to Develop Capital Markets to Enhance Liquidity and Increase Capital Flows ${ }^{20}$}

The Morgan Stanley Capital International (MSCI) Emerging Markets Index is an index used to measure equity market performance in global emerging markets and is the de facto index used by investors to channel investments to growth markets. The MSCI Emerging Markets Index grew from 10 countries in 1988 to 24 countries today and represents $13 \%$ of world market capitalisation. Most developing countries are currently not part of this index and need to explore ways how to upgrade from Frontier to Emerging Market status. To upgrade from Frontier to Emerging Market is relatively straightforward (Table 2), while the benefits are significant.

The benefits include as follows:

\footnotetext{
${ }^{20}$ This section is based on a presentation made by Prof. Alexander Van de Putte at the Belt, Road \& Bridge: Creating New China-Europe Connections conference on 1 May 2019 in London and was published in the CISI Review, the journal of the Chartered Institute for Securities \& Investments, as 'Growing the Digital Economy', by Alexander Van de Putte and George Littlejohn.
} 


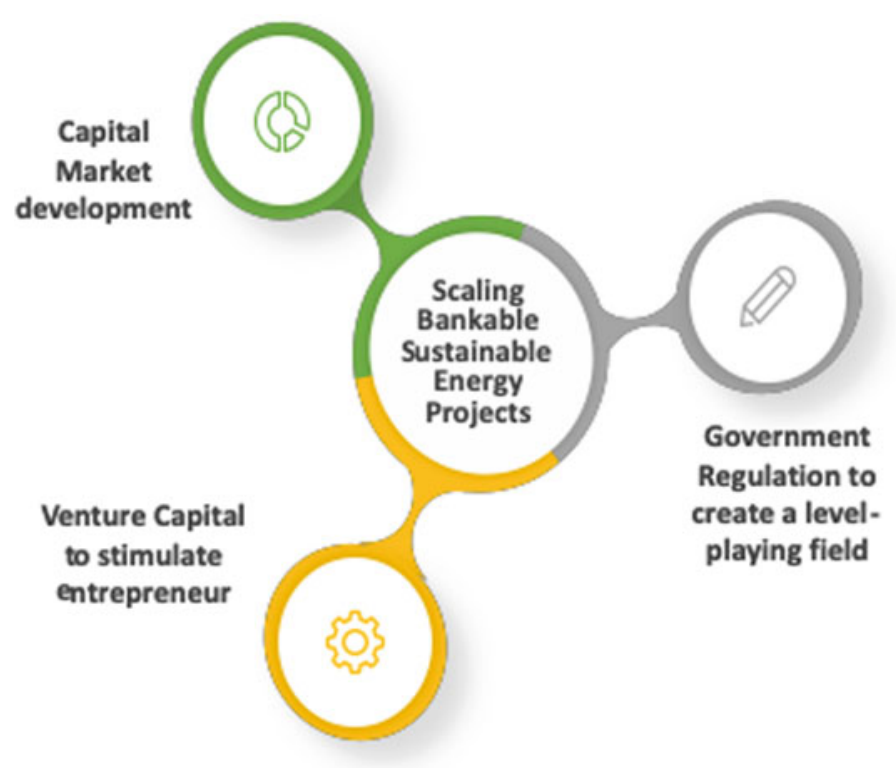

Fig. 1 Scaling the Sustainable Energy Transition

- Increased capital inflows: The MSCI Emerging Markets Index has over \$2 trillion of assets benchmarked against it. Inclusion in the Index would not only increase the exposure of developing countries' stocks to international investors, but also lead to passive inflows from funds that follow the Index's progress.

- Enhanced liquidity: Liquidity in developing countries' stock markets is typically very low. Capital inflows resulting from inclusion in the Index will substantially boost liquidity in developing countries' stock markets and economies.

- Reduced cost of capital resulting from increased trading volumes: Being part of the Index should lead to a fall in the equity risk premium because of risk diversification. This will help draw in new investors, such as endowment funds and hedge funds. As stock prices swell as a result, even more investors are drawn to developing countries, effectively creating a virtuous circle.

Apart from equity, capital markets have an important role to play in the development of debt capital markets, in particular a green bond market. The issuance of green bonds has been growing rapidly to reach $\$ 162$ billion in 2017 globally (Chartered Banker Institute 2019). Green bonds are issued to finance environmentally friendly projects, such as renewable energy projects, sustainable buildings and circular economy projects. According to the Climate Bonds Initiative (2018), most of the green bond proceeds were allocated to renewables energy projects $(39 \%)$, followed by buildings (25\%) and transportation (15\%).

To facilitate the growth of green bonds, many stock exchanges and/or regulators around the world have released national green bond guidelines and listing rules 
Table 2 MSCI Market Classification Framework and Requirements

\begin{tabular}{|c|c|c|c|}
\hline Criteria & Frontier & Emerging & Developed \\
\hline $\begin{array}{l}\text { A. Economic Development } \\
\text { A.1 Sustainability of } \\
\text { economic development }\end{array}$ & No requirement & No requirement & $\begin{array}{l}\text { Country GNI per capita } \\
25 \% \text { above the World Bank } \\
\text { high income threshold }{ }^{\mathrm{a}} \text { for } \\
3 \text { consecutive years }\end{array}$ \\
\hline $\begin{array}{l}\text { B. Economic Development } \\
\text { B.1 Number of companies } \\
\text { meeting the following } \\
\text { Standard Index criteria } \\
\text { - Company size (full } \\
\text { market cap) } \\
\text { - Security size (float } \\
\text { market cap) } \\
\text { - Security liquidity }\end{array}$ & $\begin{array}{l}3 \\
\$ 776 \mathrm{~mm} \\
\$ 776 \mathrm{~mm} \\
2.5 \% \text { ATVR }\end{array}$ & $\begin{array}{l}3 \\
\$ 1,551 \mathrm{~mm} \\
\$ 776 \mathrm{~mm} \\
15 \% \text { ATVR }\end{array}$ & $\begin{array}{l}5 \\
\$ 3,102 \mathrm{~mm} \\
\$ 1,551 \mathrm{~mm} \\
20 \% \text { ATVR }\end{array}$ \\
\hline $\begin{array}{l}\text { C. Market Accessibility } \\
\text { Criteria } \\
\text { C. } 1 \text { Openness to foreign } \\
\text { ownership } \\
\text { C. } 2 \text { Ease of capital } \\
\text { inflows/outflows } \\
\text { C. } 3 \text { Efficiency of } \\
\text { operational framework } \\
\text { C. } 4 \text { Availability of } \\
\text { investment instrument } \\
\text { C. } 5 \text { Stability of the } \\
\text { institutional framework }\end{array}$ & $\begin{array}{l}\text { At least some } \\
\text { At least partial } \\
\text { Modest } \\
\text { High } \\
\text { Modest }\end{array}$ & $\begin{array}{l}\text { Significant } \\
\text { Significant } \\
\text { Good and tested } \\
\text { High } \\
\text { Modest }\end{array}$ & $\begin{array}{l}\text { Very high } \\
\text { Very high } \\
\text { Very high } \\
\text { Unrestricted } \\
\text { Very high }\end{array}$ \\
\hline
\end{tabular}

Source MSCI, 2019 (https://www.msci.com/documents/1296102/1330218/MSCI_Global_ Market_Framework_2019.pdf/57f021bc-a41b-f6a6-c482-8d4881b759bf (accessed 17 July 2019)) ${ }^{a}$ High income threshold for 2018: GNI per capita of $\$ 12,056$ (World Bank, Atlas method)

${ }^{\mathrm{b}}$ Minimum in use for the May 2019 Semi-Annual Index Review, updated on a semi-annual basis

(Sustainable Banking Network 2018). Other markets, such as the EU, are also in the process of developing their green bond standards (EU 2019) or trying to encourage greater uptake of their green bonds as in the case with Japan (EF 2019).

Small and Medium-Sized Enterprises (SMEs) play a critical role in the economy. They tend to be nimbler and more dynamic compared to larger companies and therefore drive innovation and more sustainable business growth. SMEs, however, need access to growth financing to scale their business. In most developing countries, a capital market for SMEs does not exist. There are, however, important benefits for developing countries to develop an SME market:

- An SME market provides access to equity capital to scale the business beyond what would be possible through Venture Capital (VC) funding;

- An SME market provides exit options for VC firms which are thus more likely to provide risk capital at earlier stages of the SME development process;

- A listing often requires SMEs to bolster their corporate governance, including the recruitment of independent non-executive directors. Thus, a well-composed 
board will help SMEs identify viable strategic growth options beyond what the founders are typically able to identify;

- Over time, a lower the cost of capital which in turn will help SMEs to grow more sustainably and

- Increased visibility to a diverse group of stakeholders, which could result in additional revenue growth.

In order though for developing countries to develop the capital markets that enable their sustainable energy transition, government policies that help create a level playing field must also be implemented.

\subsection{Government Regulations to Create a Level Playing Field}

Based on the latest US Energy Information Administration (2019) report on levelised cost of new electricity generation technologies entering service in 2023, electric renewables are and will increasingly be competitive against fossil fuel alternatives from a plant investment perspective. The levelised 'investment' cost in \$/MWh of selected new generation resources entering service in 2023 is as follows: hydroelectric (39.1), onshore wind (55.9), solar PV (60), conventional combined cycle (46.3), coal with $30 \%$ carbon capture and storage (104.3) and advanced nuclear (77.5). ${ }^{21}$

When both the direct and indirect subsidies will be phased out, both wind and solar integrated as part of smart grids and combined with advanced electric storage solutions will be competitive in most geographic locations, even when the various load factors are taken into account.

But more needs to be done by governments to stimulate the uptake of renewable energy projects. Governments have a variety of policy tools available to de-risk renewable energy projects. Now that the Paris Agreement and the UN Sustainable Development Goals have been ratified by 185 states plus the EU ${ }^{22}$ and 193 countries, respectively, ${ }^{23}$ governments around the world could provide an important stimulus to sustainable economic development.

The first step is to gradually phase out the direct subsidies. The second step is to internalise the externalities. Given that the externalities constitute by far the largest share of the subsidies that benefit the fossil fuel industry, this would make the fossil fuel industry instantly uncompetitive. A rapid internalisation of the externalities is very unlikely though because many natural resource-rich countries depend on it for their economic development and they need time to diversify their economies away from fossil fuels. A gradual internalisation of the externalities combined with scaling CE projects should attract most of the investment in the short to medium term. For

\footnotetext{
${ }^{21}$ Note that comparing different technologies using LCOE alone evaluates only the cost to build and operate a plant and the value of the plant's output to the electric grid. This because different generation technology have different load factors.

${ }^{22} \mathrm{https}: / / \mathrm{www}$. unfccc.int/process/the-paris-agreement/status-of-ratification (accessed 6 July 2019).

${ }^{23} \mathrm{https}: / /$ www.sustainabledevelopment.un.org/memberstates.html(accessed 6 July 2019).
} 
natural resource-rich countries, a CE should be particularly appealing during the transition period because it would allow for making existing assets more sustainable and competitive. This, because there are many opportunities to reduce, reuse and recycle waste in the extraction industries value chain by leveraging skills, enabling infrastructure and SMEs. The circular economy in natural resource-rich countries will create skills, jobs, maintain and improve (or at least help maintain) natural capital, and create financial capital that is not dependent on the volatility of the demand for natural resources.

\subsection{A Venture Capital Approach to Sustainable Investment Is Needed $^{24}$}

Foreign Direct Investment (FDI) into especially natural resource-rich countries still tends to target the extraction industries. Of the \$4.1 trillion of global FDI flows in 2017, \$2.3 trillion (56.1\%) went into the primary sector ${ }^{25}$ (UNCTAD 2018, p. 75). These global FDI flows therefore do not help in making the energy transition a reality. Instead, a Venture Capital (VC) approach could help accelerate the sustainable energy transition, and stimulate innovation and entrepreneurship.

The life cycle of green finance projects can be broken down into three discrete yet integrated stages: (1) Ideation and business case development, (2) Independent verification and project financing and (3) Implementation and post-implementation monitoring. Note that the green financing life cycle is a non-linear process with many feedback loops. The feedback loops exist to make the business case more robust or allow the entrepreneur or investor to revisit or abandon the project at any stage of its life cycle.

\section{Stage 1: Ideation and business case development}

During this stage (Fig. 2), entrepreneurs generate ideas for sustainable energy projects. Sustainable energy projects typically fall into two categories: (1) new renewable energy generation, storage and transmission technologies and solutions and (2) $\mathrm{CE}$ technologies to ensure that waste produced during one process is used as an input into another process. This eliminates, or at least dramatically reduces, waste while creating a financial return and higher skilled jobs.

For example, technology to convert the flue gases of coal-fired power plants into cement could potentially be considered as 'green financeable', subject to results from the independent review that shows that by doing so all the capital stocks are grown and balanced simultaneously.

Most projects will not meet both the financial and ESG viability criteria (Phase 3). A potential project may be a great idea from the perspective of the inventor, but not

\footnotetext{
${ }^{24}$ This section is derived from the Astana International Financial Centre (AIFC) Unified Strategy developed in 2018.

${ }^{25}$ UNCTAD defines the primary sectors as the extraction of crude petroleum and natural gas and the mining of metal ores.
} 


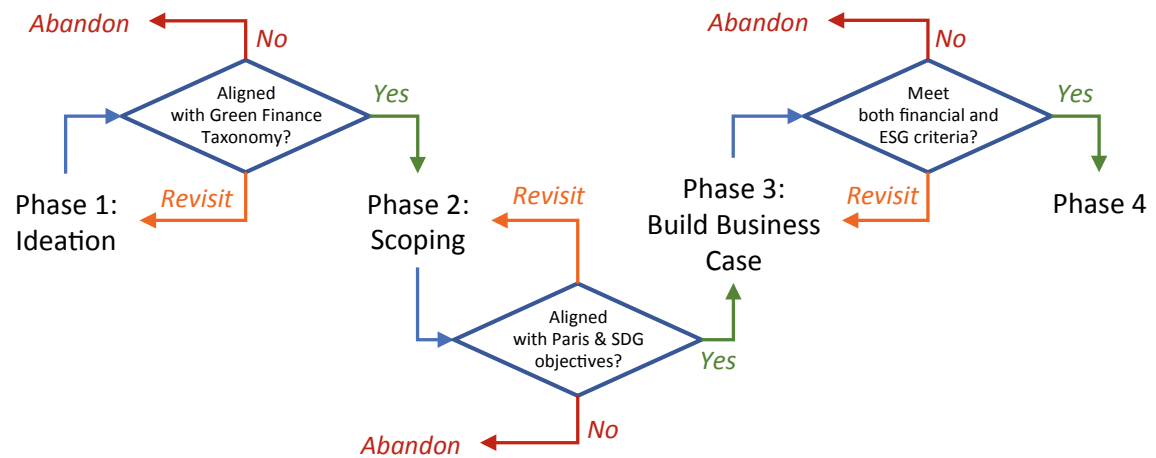

Fig. 2 Ideation and business case development stage. Source AIFC Unified Strategy, 2018

necessarily from the perspective of other stakeholders, including society at large and investors. That is the nature of entrepreneurship — it carries important risks. Stage 1 is, however, a critical stage, because entrepreneurs do not shy away from challenges. Instead, they learn from past experience and make improvements along the way, even starting afresh if need be.

\section{Stage 2: Independent verification and project financing}

After the project has demonstrated potential from a sustainability and financial return perspective, the project moves into the independent verification and project financing stage (Fig. 3). For green bonds, strict requirements need to be met to ensure that the bonds meet the local and/or internal ESG standards. For this, an external review and independent verification are required. The climate bonds initiative has issued guidelines for the issuance of climate bonds. ${ }^{26}$ Independent verification is a key

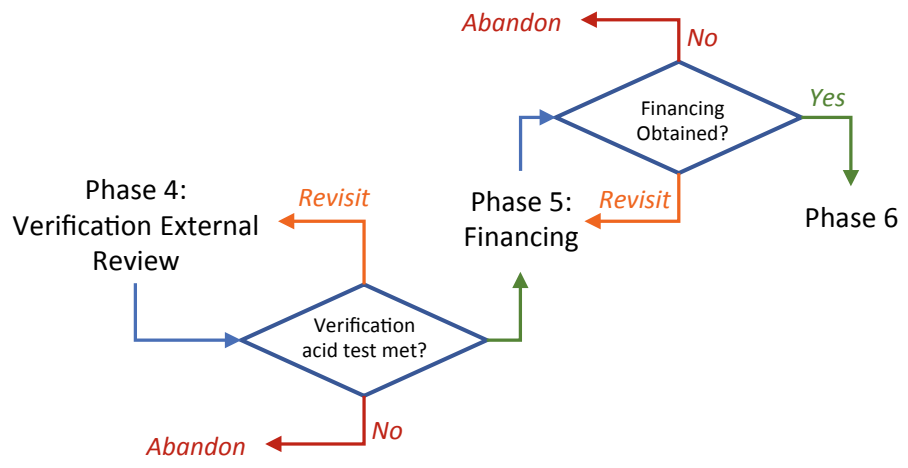

Fig. 3 Independent verification and project financing stage. Source AIFC Unified Strategy, 2018

\footnotetext{
${ }^{26}$ https://www.climatebonds.net/certification/get-certified-1 (accessed 27 July 2019).
} 


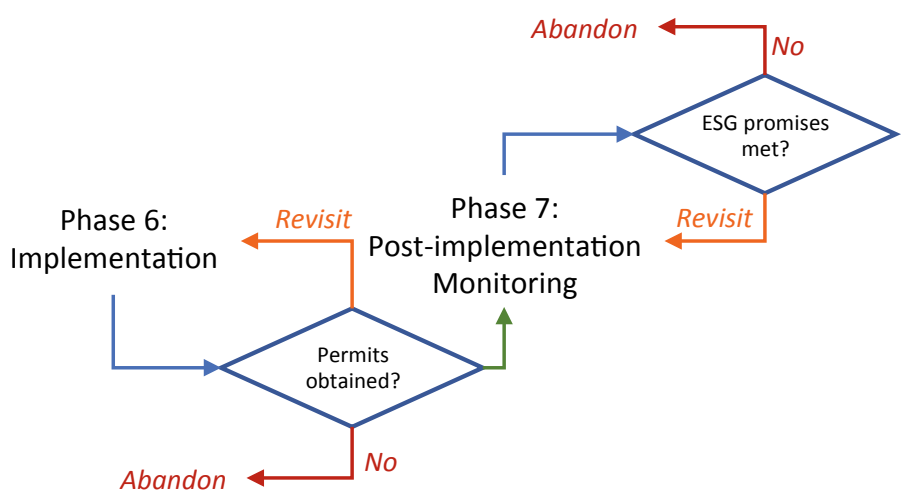

Fig. 4 Implementation and post-implementation monitoring stage. Source AIFC Unified Strategy, 2018

requirement before issuing a green bond in order to ensure that the investment meets the stated sustainable benefits, and thus to avoid 'greenwashing'. ${ }^{27}$

VC-backed green investments do not typically require an independent verification, after all the fund, and not bond market investors, bare the risk of the investment decision. However, VC funds have their own experts who conduct pre-investment due diligence, including ESG compliance of projects.

Only after the pre-investment due diligence process will an appropriate VC fund ${ }^{28}$ consider investing in a green finance project. Usually, financing will come in stages so that the VC fund can better manage the investment risk.

\section{Stage 3: Implementation and post-implementation monitoring}

After financing has been obtained the hard work starts and the focus now switches to the implementation and post-implementation monitoring phase (Fig. 4). Monitoring is important to ensure that both compliance and performance criteria are met. Compliance criteria typically relate to ESG factors, while performance criteria typical relate to financial return factors, such as Internal Rate of Return (IRR), cost overruns and delays.

Note that apart from the aforementioned feedback loops, the flexibility in the life cycle of sustainable energy finance projects remains to also abandon the project. Abandonment may take many dimensions-from stopping a project to handing it over to a different type of investor. VC funds typically bring more than just equity finance to the sustainable energy project; they often lie in the trenches and assist in strategic and operational matters.

\footnotetext{
${ }^{27}$ Greenwashing can be defined as 'the practice of making an unsubstantiated or misleading claim about the environmental benefits of a product, service, technology or company practice'. https://whatis.techtarget.com/definition/greenwashing (accessed 24 July 2019).

${ }^{28}$ Various types of VC funds exist. Some will invest in early stage ventures, some during the growth stage and yet others help companies to prepare for a public offering.
} 
The life cycle of green finance projects is designed to simultaneously achieve several objectives: (1) stimulate entrepreneurship; (2) obtain financing for ESG compliant projects; (3) reduce risk through independent review and verification, thus improving the bankability of green finance projects and (4) continuously monitor progress made to allow for taking corrective action as needed and develop a knowledge base for future green finance projects.

\section{Conclusion}

There is no shortage of capital, nor is there a shortage of bankable ideas to make the sustainable energy transition a reality. The challenge is that systematic change is needed for governments around the world to deliver on the commitments they have made following the ratification of the SDGs and the Paris Agreement. It is also important to create a level playing field and gradually eliminate the direct subsidies and internalise the indirect subsidies benefitting the fossil fuel industry. Finally, especially developing countries need to develop both capital markets and make venture capital financing available to entrepreneurs. Top-down forward-looking government policy combined with bottom-up entrepreneurs would dramatically accelerate the sustainable energy transition because capital would increasingly be channelled towards bankable sustainable projects.

Acknowledgement The authors would like to thank Dr. Kairat Kelimbetov, Governor of the AIFC for his insights and for allowing us to use some of the AIFC development strategy ideas and concepts.

\section{References}

Amundi (2018) How ESG Investing Has Impacted the Asset Pricing in the Equity Market (online). Available from http://research-center.amundi.com/ezjscore/call/ ezjscamundibuzz::sfForwardFront::paramsList=service=ProxyGedApi\&routeId=_dl_ MjcxZGQxOGJkMGEyYmMwZTdiNGY1ODNiMjMyMzdiN2I. Accessed 18 July 2019

Apparicio S, Sauer N (2018) Which countries have not ratified the Paris climate agreement? Available from https://www.climatechangenews.com/2018/07/12/countries-yet-ratifyparis-agreement. Accessed 17 July 2019

Boston Consulting Group (2019) Global Wealth: Reigniting Radical Growth. Available from https://www.bcg.com/en-be/publications/2019/global-wealth-reigniting-radical-growth.aspx. Accessed???

Carrington D (2019) Worrying' rise in global CO2 forecast for 2019. The Guardian (online). Available from https://www.theguardian.com/environment/2019/jan/25/worrying-rise-in-global-co2forecast-for-2019. Accessed 16 July 2019

Chartered Banker Institute (2019) Principles and Practice of Green Finance 2019

Climate Action Tracker (2017) Trump's climate policies would see US climate action rating drop from "medium" to "inadequate". Available from https://climateactiontracker.org/publications/ 
trumps-climate-policies-would-see-us-climate-action-rating-drop-from-medium-to-inadequate. Accessed 17 July 2019

Climate Bonds Initiative (2018) Q2 2018 Green Bonds Market Summary. Available from https:// www.climatebonds.net. Accessed 21 July 2019

Ellen MacArthur Foundation (2013) Towards the Circular Economy: Economic and business rationale for an accelerated transition. Ellen MacArthur Foundation, Cowes

ENI (2018) World Energy Outlook: looking ahead to 2040. Available from https://www.eni.com/ en_IT/investors/global-energy-scenarios/world-energy-outlook.page\#. Accessed 15 July 2019

Environmental Finance (EF) (2019) The green bond market looks east. Available from https:// www.environmental-finance.com/content/the-green-bond-hub/the-green-bond-market-lookseast.html. Accessed 18 July 2019

Erickson A (2018) Few countries are meeting the Paris climate goals. Here are the ones that are. The Washington Post. Available from https://www.washingtonpost.com/world/2018/10/11/fewcountries-are-meeting-paris-climate-goals-here-are-ones-that-are/?utm_term=.e9b6ad570815. Accessed 17 July 2019

European Union (EU) (2019) Report of the Technical Expert Group (TEG) Subgroup on Green Bond Standard: Proposal for an EU Green Bond Standard. Available from https://ec.europa.eu/info/ sites/info/files/business_economy_euro/banking_and_finance/documents/190306-sustainablefinance-teg-interim-report-green-bond-standard_en_0.pdf. Accessed 18 July 2019

Giese G, Lee L-E, Melas D, Nagy Z, and Nishikawa L (2019) Foundations of ESG investing: how ESG affects equity valuation, risk, and performance. J Portfolio Manag 45(5):4-11. Available from http://info.msci.com/foundations-of-ESG-investing-part1. Accessed 19 July 2019

Global Sustainable Investment Alliance (GSIA) (2017) Global Sustainable Investment Review 2018. Available from http://www.gsi-alliance.org/wp-content/uploads/2019/03/GSIR_Review2018.3. 28.pdf. Accessed on 17 July 2019

International Energy Agency (IEA) (2018) World Energy Outlook 2018. Available from https:// www.iea.org/weo2018/scenarios. Accessed on 17 July 2019

Coady D, Parry I, Le N-P, Shang B (2019) Global fossil fuel subsidies remain large: an update based on country-level estimates. In: International Monetary Fund (IMF). Available from https://www.imf.org/en/Publications/WP/Issues/2019/05/02/Global-Fossil-FuelSubsidies-Remain-Large-An-Update-Based-on-Country-Level-Estimates-46509. Accessed on 1 Aug 2019

Liu Z (2015) Global energy interconnection. Academic Press, London

McKinsey and Company (2015) Europe's circular-economy opportunity. Available from https:// www.mckinsey.com/business-functions/sustainability/our-insights/europes-circular-economyopportunity. Accessed 17 July 2019

Mooney A (2018) Rising investor interest pushes ESG funds past \$1tn. Financial Times. Available from https://www.ft.com/content/f1e98ec7-083e-3b95-8c6b-ecc4810b988e. Accessed on 19 July 2019

Mooney C, Dennis B (2018) The world has just over a decade to get climate change under control, UN scientists say. The Washington Post. Available from https://www.washingtonpost.com/ energy-environment/2018/10/08/world-has-only-years-get-climate-change-under-control-unscientists-say/?utm_term=.93c8bb06fd33. Accessed 17 July 2019

Morgan Stanley Capital International (MSCI) (2017) Swipe right to invest: Millennials and ESG, the perfect match? Available from https://www.msci.com/documents/10199/07e7a7d3-59c3-4d0bb0b5-029e8fd3974b. Accessed 16 July 2019

Morgan Stanley Capital International (MSCI) (2019a) MSCI announces the results of the 2019 annual market classification review. Available from https://www.msci.com/market-classification. Accessed on 24 July 2019

Morgan Stanley Capital International (MSCI) (2019b) MSCI Market Classification Framework. Available from https://www.msci.com/market-classification. Accessed on 23 July 2019 
Morgan Stanley Institute for Sustainable Investing (2017) Sustainable Signals, New Data from the Individual Investor Available from https://www.morganstanley.com/pub/content/dam/msdotcom/ ideas/sustainable-signals/pdf/Sustainable_Signals_Whitepaper.pdf. Accessed on 17 July 2019

S\&P (2019) S\&P Dow Jones Indices. Available from https://us.spindices.com/indices/equity/spasx-200-esg-index-\$. Accessed 19 July 2019

Steadman R (2019) Why Facebook Was Dropped from the S\&P 500® ESG Index. Indexology Blog. Available from https://www.indexologyblog.com/2019/06/11/why-facebook-wasdropped-from-the-sp-500-esg-index. Accessed 19 July 2019

Sustainable Banking Network (2018) Creating Green Bond Markets-Insights, Innovations, and Tools from Emerging Markets. IFC, Washington

The Guardian (2019) 'Worrying' rise in global CO2 forecast for 2019. Available from https:// www.theguardian.com/environment/2019/jan/25/worrying-rise-in-global-co2-forecast-for2019. Accessed on 18 July 2019

Tyson JE (2018) Private infrastructure financing in developing countries: Five challenges, five solutions. Overseas Development Institute Working Paper 536. Available from https://www.odi. org/sites/odi.org.uk/files/resource-documents/12366.pdf. Accessed 24 July 2019

United Nations (2019a) World Population Prospects 2019. Available from https://population.un. org/wpp/DataQuery. Accessed 15 July 2019

United Nations (2019b) Sustainable Development Goals. Available from https://www.un.org/ sustainabledevelopment. Accessed 16 July 2019

United Nations Conference on Trade and Development (UNCTAD) (2014) The World Investment Report 2014. Investing in the SDGs: An Action Plan. United Nations, NY and Geneva. Available at https://unctad.org/en/PublicationsLibrary/wir2014_en.pdf

United Nations Conference on Trade and Development (UNCTAD) (2018) World Investment Report: Investment and New Industrial Policies. United Nations, NY and Geneva. Available at https://unctad.org/en/PublicationsLibrary/wir2018_en.pdf

United Nations Framework Convention on Climate change (UNFCCC) (2019) Available from https://unfccc.int/process/the-paris-agreement/status-of-ratification. Accessed on 16 July 2019

US Energy Information Administration (2019) Levelized Cost and Levelized Avoided Cost of Generation Resources in the Annual Energy Outlook 2019. Available from https://www.eia.gov/ outlooks/aeo/pdf/electricity_generation.pdf. Accessed 25 July 2019

Van de Putte A (2010) Trade and energy: a new clean energy deal. In: Lehmann F, Lehmann J-P (eds) Peace and prosperity through world trade. Cambridge University Press, Cambridge, pp 201-206

Van de Putte A, Kelimbetov K, Holder A (eds) (2017) The perfect storm: navigating the sustainable energy transition. Sustainable Foresight Institute, Brussels

Van de Putte A, Nematova S (2017) Electric renewables: the storage, intermittency and scalability challenge In: Van de Putte A, Kelimbetov K, Holder A (eds) The perfect storm: navigating the sustainable energy transition. Sustainable Foresight Institute, Brussels, pp 165-183

Zhou M (2019) ESG, SRI and Impact Investing: What's the Difference? Available from https://www. investopedia.com/financial-advisor/esg-sri-impact-investing-explaining-difference-clients.

Accessed on 23 July 2019 
Open Access This chapter is licensed under the terms of the Creative Commons Attribution 4.0 International License (http://creativecommons.org/licenses/by/4.0/), which permits use, sharing, adaptation, distribution and reproduction in any medium or format, as long as you give appropriate credit to the original author(s) and the source, provide a link to the Creative Commons license and indicate if changes were made.

The images or other third party material in this chapter are included in the chapter's Creative Commons license, unless indicated otherwise in a credit line to the material. If material is not included in the chapter's Creative Commons license and your intended use is not permitted by statutory regulation or exceeds the permitted use, you will need to obtain permission directly from the copyright holder.

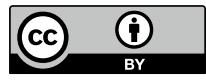

